\title{
Effects of Heating Temperature and Load Weight on Rheological Properties of Waste Plastic Cup
}

\author{
Halimatuddahliana Nasution* and Winny \\ Department of Chemical Engineering, Faculty of Engineering, Universitas \\ Sumatera Utara, Padang Bulan 20155, Medan, Indonesia \\ "Corresponding author: h_dahliana@yahoo.com
}

Published online: 31 May 2021

To cite this article: Halimatuddahliana Nasution and Winny (2021). Effects of heating temperature and load weight on rheological properties of waste plastic cup. Journal of Engineering Science, 17(1), 39-49, https://doi.org/10.21315/jes2021.17.1.3.

To link to this article: https://doi.org/10.21315/jes2021.17.1.3

\begin{abstract}
Analysis of heating temperature and load weight to the rheological properties of waste plastic cups is very important to gain fundamental understanding of the structure, characteristics, and processability of the material. The samples were tested using melt flow indexer. The heating temperature investigated were $180^{\circ} \mathrm{C}, 190^{\circ} \mathrm{C}, 200^{\circ} \mathrm{C}, 210^{\circ} \mathrm{C}$, $220^{\circ} \mathrm{C}$ and $230^{\circ} \mathrm{C}$, and the weight load were $1,875 \mathrm{~g}, 2,160 \mathrm{~g}, 2,835 \mathrm{~g}, 3,035 \mathrm{~g}$ and $3,450 \mathrm{~g}$. The results obtained showed that the rheological properties of products such as melt flow index, shear stress and shear rate increased and the viscosity decreased with the increasing of heating temperature and load weight. For higher heating temperatures, the melt flow index, shear stress and shear rate of waste plastic cup increased significantly with the increasing load weight whereas the viscosity of waste plastic cup did not decrease significantly with the increasing load weight.
\end{abstract}

Keywords: heating temperature, load weight, waste plastic cup, rheology

\section{INTRODUCTION}

In recent years, there is a significant increase in the production and application of non-biodegradable materials such as plastic in beverage packaging. Plastic is used because of its several advantages, such as flexibility, low price and chemical resistance. This has led to an increase amount of plastics that end up as waste. About $4 \%$ of them are waste plastic cups. ${ }^{1}$ 
Waste plastic cups are the remains of plastic mineral water containers in the form of cup. ${ }^{2}$ One of the thermoplastic materials used as raw material for plastic cup is polypropylene (PP). A recycling logo is printed with the number 5 in the middle, as well as PP inscription. ${ }^{3}$

One of the methods to reduce the amount of waste plastic cup in the environment is the reuse of PP waste with a recycling process to produce new products with low production costs. ${ }^{4}$ Recycling of PP as a thermoplastic plastic is carried out by melting and extrusion processes so that it solidifies and forms a product. These processes depends on the nature of the material flow. Therefore, analysis of the rheological properties of waste plastic cups is very important to gain fundamental understanding of the structure, characteristics, and processability of the material. ${ }^{5}$ The rheological properties are investigated in order to characterise the flow deformation of waste plastic cup, especially during melt processing. ${ }^{6}$ The rheological properties of other waste plastic materials has also been extensively studied, such as polyethylene terephthalate (PET), polycarbonate (PC) and polyvinyl chloride (PVC). ${ }^{7-10}$

Several studies have been done regarding the properties of pure and recycled PP materials. The mechanical and rheological properties of pure PP was examined by Incarnato et al. ${ }^{7}$ The recycling process causes the deformation of pure PP and a decrease in PP viscosity due to the decrease in molecular weight. The effect of recycling PP plastic from pure PP was studied by Jun and Juwono. ${ }^{11}$ Recycled PP causes a reduction in elongation-at-break so that recycled PP is more brittle than pure PP. Rohitha et al. ${ }^{12}$ examined the effect of temperature changes on the mechanical and rheological properties of recycled PP. Increasing temperature causes a decrease in shear stress, fracture strength and fracture strain. Meng et al. ${ }^{13}$ examined the effect of die diameter and operating temperature on the viscosity of recycled PP. A decrease in die diameter and operating temperature leads to an increase in the viscosity of recycled PP. From these studies, it can be seen that research on the rheological properties of waste plastic cup needs to be done because its molecular structure and material characteristics are different from pure PP material.

Before the waste plastic cups are converted into a product, the materials will go through a forming process that involves deformation and flow as the core of rheology. ${ }^{14}$ Since polymer melts are viscoelastic, their viscosity and elasticity must be measured. ${ }^{15}$ Viscoelasticity is a key rheological parameter that indicates the use and processability of PP materials in waste plastic cups. ${ }^{16}$ The low viscosity of PP plastic melts provides the advantages of ease of flow, reduced extuder energy and affects the elasticity of polymer melt. ${ }^{17}$ 
Heating temperature and load weight affect the viscosity of molten polymer.The viscosity of the molten polymer decreases with the increase of heating temperature. ${ }^{16}$ Load weight is related to pressure. High pressure causes a significant increase in the viscosity of the molten polymer. ${ }^{18}$ Therefore, the suitable processing conditions will result in a product with good properties. The aim of this research is to study the effects of the heating temperature and load weight on rheological properties of the waste plastic cups which includes the melt flow index, shear stress, shear rate and viscocity.

\section{MATERIALS AND METHODS}

\subsection{Preparation of Waste Plastic Cup Samples}

Waste plastic cups were collected and selected, in which the type plastic used was PP with code 5. Waste plastic cup samples were cleaned/washed from the dirt and then dried. Furthermore, waste plastic cup samples were cut into small pieces.

\subsection{Testing and Characterisation Analysis}

For this testing, $6 \mathrm{~g}$ of waste plastic cup sample was weighed. The melt flow indexer control handle was set to the "block" position as the cylinder was cleaned previously. The machine was turned on by pressing the "power" button. The load was varied under $1,875 \mathrm{~g}, 2,160 \mathrm{~g}, 2,835 \mathrm{~g}, 3,035 \mathrm{~g}$ and 3,450 g, respectively. The experiment also occured at different heating temperature. They were varied $180^{\circ} \mathrm{C}, 190^{\circ} \mathrm{C}, 200^{\circ} \mathrm{C}, 210^{\circ} \mathrm{C}, 220^{\circ} \mathrm{C}$ and $230^{\circ} \mathrm{C}$. After reaching the operation condition, the die was placed and rod was loaded into the cylinder for $15 \mathrm{~min}$. The sample was put into the cylinder with the help of a bakelite funnel. Then, the load rod was inserted again into the cylinder and pressed to remove air bubbles in the sample. The sample was pre-heated for $4 \mathrm{~min}$ and set the control handle to the "open" position. The output extrudate was cut every $30 \mathrm{sec}$ and taken five times. Finally, the mass of the extrudates was weighed. Figure 1 shows the melt flow indexer equipment. 


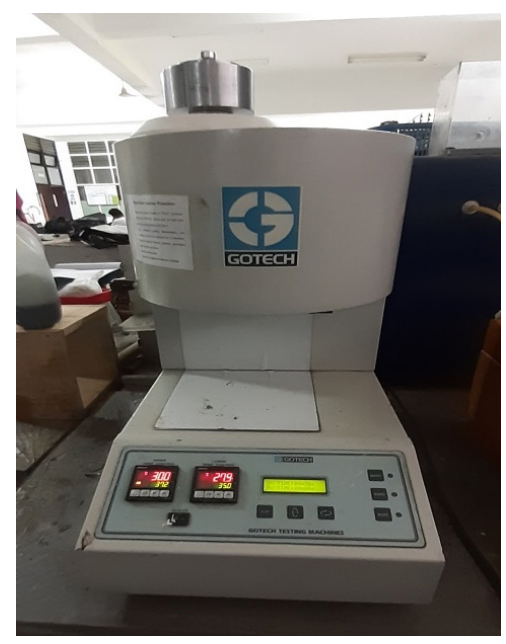

Figure 1: Melt flow indexer.

\subsection{Testing of Waste Plastic Cup Extrudate}

Testing was conducted using Melt Flow Indexer Model GOTECH 7100 (as shown in Figure 1). Test method is done to get the melt flow index, shear stress, shear rate and viscosity.

\subsubsection{Analysis of melt flow index accordance to ASTM D1238}

Melt flow index values for specimens tested were calculated using Equation 1.

$$
\text { Melt flow index }=\frac{m}{t} \times 600
$$

where $m$ and $t$ are mass of extrudate and cutting time, respectively.

\subsubsection{Analysis of shear stress accordance to ASTM D1238}

Shear stress values for specimens tested were calculated using Equation 2.

$$
\text { Sheer stress } \mathrm{app}_{\mathrm{ap}}=\frac{R P}{2 L}
$$

where $R, P$ and $L$ are radius of die, pressure and length of die, respectively. In this research, the Bagley correction was not conducted as the length-to-diameter $(L / R)$ ratio remained constant. 


\subsubsection{Analysis of shear rate accordance to ASTM D1238}

Shear rate values for specimens tested based on Rabinowitch Equation were calculated using Equation 3.

$$
\text { Shear rate } \text { cor }=\frac{4 Q}{\pi R^{3}} \times \frac{(3 n+1)}{4 n}
$$

where $Q, R$ and $n$ are volumetric flow rate, radius of die and slope, respectively.

\subsubsection{Analysis of viscosity}

Viscosity values for specimens tested were calculated using Equation 4.

$$
\text { Viscosity }_{\mathrm{app}}=\frac{\text { Sheer stress }_{\text {app }}}{\text { Sheer stress }_{\text {cor }}}
$$

\section{RESULTS AND DISCUSSION}

\subsection{The Effects of Heating Temperature and Load Weight on Melt Flow Index of Waste Plastic Cup}

Figure 2 shows the effect of heating temperature and load weight on the melt flow index of waste plastic cup. It can be seen from the graph that the melt flow index of waste plastic cup has increased with increasing heating temperature and load weight.

The melt flow index value increases with increasing heating temperature. This happened because the increasing of heating temperature will cause the polymer to become more diluted/melted due to the increasing energy of the polymer molecules to flow. The volume of melted polymer that comes out each cut-off time and the extrudate mass will increase too. In addition, the melt flow index value increases with increasing weight. This is because the increasing load weight will give enought pressure which encourages more melted polymer to come out each cut-off time so that the extrudate mass increases.

For higher heating temperatures, the melt flow index of waste plastic cup increases significantly with increasing load weight. This is because there is an increase in pressure which causes chain slip and easier molecular mobility. Thus, the viscosity of the fluid decreases. ${ }^{19}$ 


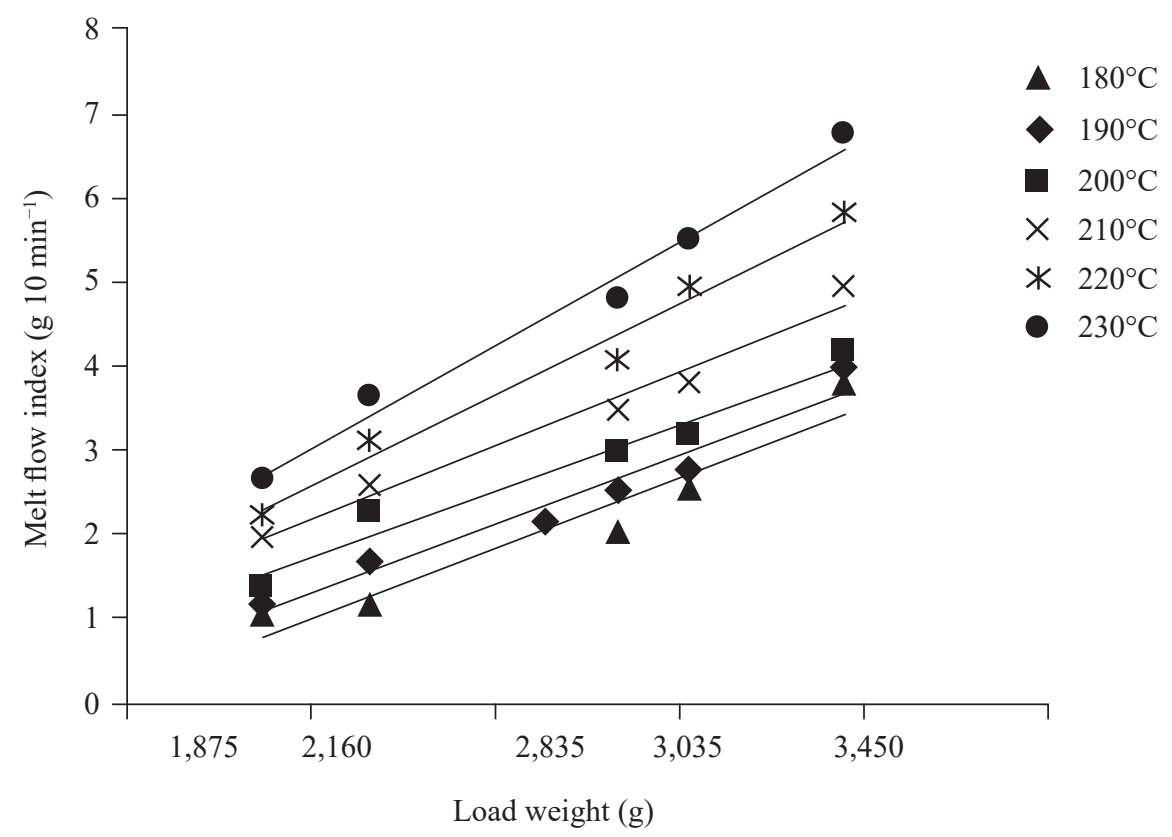

Figure 2: The effect of heating temperature and load weight on melt flow index of waste plastic cup.

\subsection{The Effects of Heating Temperature and Load Weight on Shear Rate of Waste Plastic Cup}

Figure 3 shows the effect of heating temperature and weight on the shear rate of waste plastic cup. Since the flow of polymer melt is non-Newtonian, the shear rate is corrected with Rabinowitch Correction. It can be seen from the graph that the relationship is linear for all shear rates, where at the same heating temperature, the shear rate increases with increasing shear stress.

By increasing the heating temperature of the waste plastic cup, the speed of molecular separation will increase so the orientation of the deformation takes place faster. Increasing the heating temperature will increase the crystallinity of the PP polymer. ${ }^{4}$ In addition, when the heating temperature increases, the polymer melt will be increasingly pseudoplastic, which is a common characteristic of thermoplastic polymers. ${ }^{21}$ Therefore, the higher the shear rate, there is less resistance and the polymer chains are easier to flow. Thus, the viscosity will decrease. 


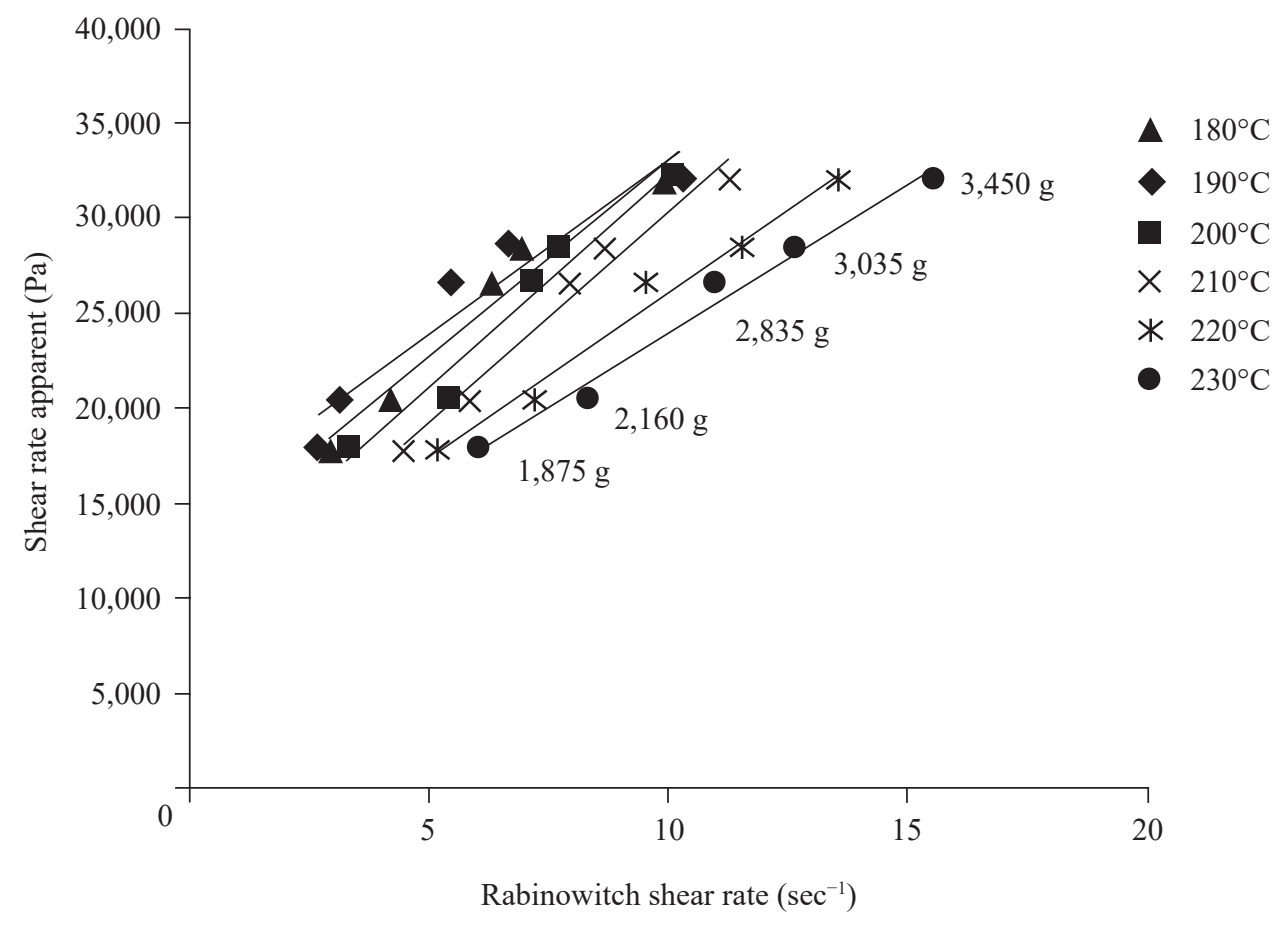

Figure 3: The effect of heating temperature and load weight on shear rate of waste plastic cup.

The value of the shear rate increases with increasing weight. This is because the additional weight of the load will provide enough pressure which increases the rate of stress fluid. This caused the amount of extrudate flowing over the same time increases. ${ }^{19}$

For higher heating temperatures, the shear rate of waste plastic cup increases significantly with increasing load weight. Load weight is related to pressure. Thus, the dependence of shear rate on pressure is increased. ${ }^{20}$

Curve lines tend to move away with increasing shear rate. Thus, the shear rate has a more significant increase for higher shear stress. This indicates a point where the deformation takes place and an increase in shear stress will have a relatively large effect on the shear rate. Hence the dependence of shear rate on shear stress increase. ${ }^{19}$ 


\subsection{The Effects of Heating Temperature and Load Weight on Viscosity of Waste Plastic Cup}

Figure 4 shows the effect of heating temperature and weigh load on the viscosity of waste plastic cup. It can be seen from the graph that the relationship is linear for all shear rates, where at the same heating temperature, the melt viscosity decreases as the shear rate decreases.

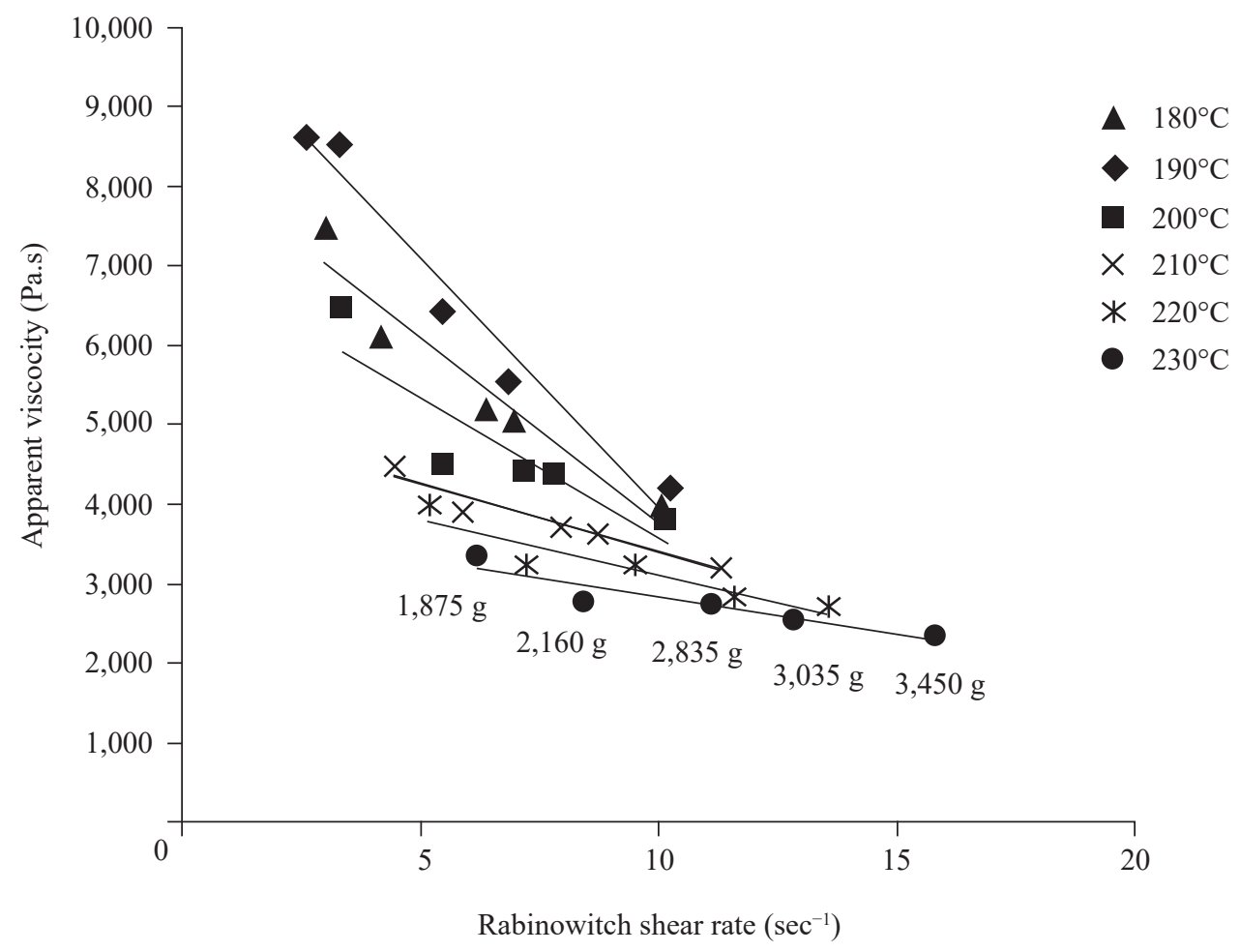

Figure 4: The effect of heating temperature and load weight on viscosity of waste plastic cup.

In plastic homopolymers used for glass packaging made from PP, there was a decrease in melt viscosity at high shear rates and melting temperatures. This results in the decrease of the surface tension of the melt, which implies less resistance for the material to flow. ${ }^{21}$ 
From a molecular point of view, material flow occurs when polymer molecules move past one another. The movement of polymer melts depends on the mobility of the molecular chains, as well as the bonds that bind polymer molecules. ${ }^{16}$ Increasing the heating temperature of the polymer will reduce the melt viscosity because there is an increase in the mobility and flexibility of the molecules of the polymer molecules and the free volume of the material. The greater the free volume, the easier the flow will be. ${ }^{22}$

The viscosity value obtained decreases with increasing load weight. This is because there is an increase in pressure which causes chain slip and easier molecular mobility. Thus, the viscosity of the fluid decreases. ${ }^{19}$

For higher heating temperatures, the viscosity of waste plastic cup did not decrease significantly with increasing load weight. Load weight is related to pressure. Thus, the dependence of viscosity on pressure is reduced. The decreasing of polymer viscocity is more pronounced on higher heating temperature than load weight. Higher heating temperature is more prominent on the molecular movement on polymer than the weight load. ${ }^{20}$

The increasing shear rate causes the viscosity of waste plastic cup tend to be close together. Viscosity tends to decrease more at low shear rates than at high shear rates. This implies that a point where a large deformation orientation has taken place and an increase in shear rate will only have a relatively small effect on the viscosity of the melt. Therefore, the dependence of the melt viscosity on shear rate decreases. ${ }^{23}$

\section{CONCLUSION}

Analysis of heating temperature and load weight to the rheological properties of waste plastic cups is very important to gain fundamental understanding of the structure, characteristics, and processability of the material. The results obtained showed that the rheological properties of products such as melt flow index, shear stress and shear rate increased and the viscosity decreased with the increasing of heating temperature and load weight. For higher heating temperatures, the melt flow index, shear stress and shear rate of waste plastic cup increased significantly with the increasing load weight whereas the viscosity of waste plastic cup did not decrease significantly with the increasing load weight. 


\section{REFERENCES}

1. The World Bank. (2018). Hotspot sampah laut Indonesia. Jakarta: The World Bank.

2. Hozairi, A. (2017). Pemanfaatan limbah gelas plastik air mineral sebagai bahan ukir bertema kehidupan anak jalanan. Jurnal Pendidikan Seni Rupa, 5(1), 19-26.

3. Karuniastuti. (2015). Bahaya plastik terhadap kesehatan dan lingkungan. Forum Teknologi, 3(1), 6-13.

4. Zdiri, K., Elamri, A., Hamdaoui, M., Harzallah, O., Khenoussi, N. \& Brendle, D. J. (2018). Reinforcement of recycled PP polymers by nanoparticles incorporation. Green. Chem. Lett. Rev., 11(3), 296-311, https://doi.org/10.1080/17518253.2018.1491645.

5. Vlachopoulos, J. \& Strutt, D. (2012). The role of rheology in polymer extrusion. Ontario, Canada: Polydynamic, Inc.

6. Ismail, H. H. \& Akil, H. M. (2005). Flow behavior of polypropylene/ ethylene-propylene diene terpolymer/natural rubber (PP/EPDM/ NR) blends by Torque rheometer: The effect of N,N-m-phenylene bismaleimide (HVA-2) addition. Polym. Plast. Technol. Eng., 44(8-9), 1429-1442, https://doi.org/10.1080/03602550500210067.

7. Incarnato, L., Scarfato, P. \& Acierno, D. (1999). Rheological and mechanical properties of recycled polypropylene. Polym. Eng. Sci., 39(4), 749-755, https://doi.org/10.1002/pen.11463.

8. Elamri, A. K., Harzallah, A. O. \& Lallam, A. (2015). Characterization of recycled/virgin PET polymers and their composites. Am. J. Nano Res. Appl., 3(4-1), 11-16.

9. Kim, H., Lee, H. \& Lee, J. W. (2007). Rheological properties of branched polycarbonate prepared by an ultrasound-assisted intensive mixer. Korea Aust. Rheol. J., 19(1), 1-5.

10. Sombasompop, N. \& Thongsang, S. (2001). Rheology, morphology, and mechanical and thermal properties of recycled PVC pipes. J. Appl. Polym. Sci., 82(10), 2478-2486, https://doi.org/10.1002/app.2098.

11. Jun, B. J. H. \& Juwono, A. L. J. (2010). Studi perbandingan sifat mekanik polypropylene murni dan daur ulang. Makara, Sains, 14(1), 95-100.

12. Rohitha, L. P. S., Perera, S. S. N. \& Prashantha, M. A. B. (2013). Mechanical properties and kinetics of weight loss of polypropylene waste plastic within the very low extent of weight loss under iso-thermal conditions. Int. Refereed J. Eng. Sci., 2(4), 11-16.

13. Meng, L., Wu, D., Kelly, A., Woodhead, M. \& Liu, Y. (2016). Experimental investigation of the rheological behaviors of polypropylene in a capillary flow. J. Appl. Polym. Sci., 133(2), 1-9, https://doi.org/10.1002/app.43459. 
14. Ariff, Z. M., Arifin, A., Jikan, S. S. \& Rahim, N. A. A. (2012). Rheological behaviour of polypropylene through extrusion and capillary rheometry. In F. Dogan (ed.), Polypropylene, 29-48. Rijeka, Croatia: Intech.

15. Sadiku-Agbolla, O., Sadiku, E. R., Adegbola, A. T. \& Biotidara, O. F. (2011). Rheological properties of polymers: Structure and morphology of molten polymer blends. Mat. Sci. Appl., 2, 30-41, https://doi.org/10.4236/ msa.2011.21005.

16. Liang, J. Z., Li, R. K. Y., Tang, C. Y. \& Cheung, S. W. (2000). Dieswell behavior of glass bead-filled low-density polyethylene composite melts at high extrusion rates. J. Appl. Polym. Sci., 76, 419-424, https://doi.org/10.1002/(SICI)1097-4628(20000418)76:3<419::AID -APP17>3.0.CO;2-B.

17. Han, C. D. (1976). Rheology in polymer processing. New York: Academic Press.

18. Driscoll, P. D. \& Bogue, D. C. (1990). Pressure effects in polymer melt rheology. J. Appl. Polym. Sci., 39(8), 1755-1768, https://doi.org/10.1002/ app.1990.070390813.

19. Darojat, I. S. (2008). Analisis pengaruh waktu pemanasan awal dan massa sampel terhadap hasil uji indeks alir lelehan polipropilena. PhD diss., Universitas Indonesia.

20. Hausnerova, B., Sedlacek, T., Slezak, R. \& Saha, P. (2006). Pressuredependent viscosity of powder injection moulding compounds. Rheol. Acta., 45, 290-296, https://doi.org/10.1007/s00397-005-0036-4.

21. Rahim, N. A. A., Ariff, Z. M. \& Ariffin, A. (2011). Flow behaviour and viscoelasticity of polypropylene-kaolin composites extruded at different temperatures. Pertanika J. Sci. Technol., 19(2), 383-388.

22. Doufas, A. K., Rice, L. \& Thurston, W. (2011). Shear and extensional rheology of polypropylene melts: Experimental and modelling studies. J. Rheol., 55(1), 95-126, https://doi.org/10.1122/1.3523626.

23. Al-Shammari, B., Al-Fariss, T., Al-Sewailm, F. \& Elleithy, R. (2011). The effect of polymer concentration and temperature on the rheological behavior of metallocene linear low density polyethylene (MLLDPE) solutions. J. King Saud Univ. Eng. Sci., 23(1), 9-14, https://doi.org/10 .1016/j.jksues.2010.07.001. 